\title{
SUGAR-FREE CHEWING GUM AND DENTAL CARIES - A SYSTEMATIC REVIEW
}

\author{
Steffen MICKENAUTSCH ${ }^{1}$, Soraya Coelho LEAL ${ }^{2}$, Veerasamy YENGOPAL ${ }^{3}$, Ana Cristina BEZERRA ${ }^{4}$, Vanessa CRUVINEL ${ }^{5}$
}

\author{
1- BDS, Division of Public Oral Health, University of the Witwatersrand, Johannesburg, South Africa. \\ 2- PhD, University of Brasilia, DF, Brazil. \\ 3- MChD, Division of Public Oral Health, University of the Witwatersrand, Johannesburg, South Africa. \\ 4- PhD, School of Dentistry, Catholic University of Brasilia, DF, Brazil. \\ 5- MS, in private practice in Brasilia, DF, Brazil.
}

Corresponding address: S Mickenautsch, BDS - Division of Public Oral Health - University Of The Witwatersrand - P.O. Box 2779

Houghton/ Johannesburg - 2041 - South Africa - Phone: 27117172594 - Fax: 27117172625 - e-mail: neem@global.co.za

Received: March 27, 2007 - Accepted: April 16, 2007

\begin{abstract}
$O$

bjective: To appraise existing evidence for a therapeutic / anti-cariogenic effect of sugar-free chewing gum for patients. Method: 9 English and 2 Portuguese databases were searched using English and Portuguese keywords. Relevant articles in English, German, Portuguese and Spanish were included for review. Trials were excluded on lack of randomisation, control group, blinding and baseline data, drop out rate $>33 \%$, no statistical adjustment of baseline differences and no assessment of clinically important outcomes. Reviews were excluded on lack of information, article selection criteria, search strategy followed, search keywords, searched databases or lack of study-by-study critique tables. In cases of multiple reports from the same study, the report covering the longest period was included. Two reviewers independently reviewed and assessed the quality of accepted articles.

Results: Thirty-nine articles were included for review. Thirty were excluded and 9 accepted. Of the 9 accepted, 2 trials of reasonable and good evidence value did not demonstrate any anti-cariogenic effect of sugar-free chewing gum. However, 7 articles, with 1 of strong, and 6 of good evidence value, demonstrated anti-cariogenic effects of chewing Sorbitol, Xylitol or Sorbitol/Xylitol gum. This effect can be ascribed to saliva stimulation through the chewing process, particularly when gum is used immediately after meals; the lack of sucrose and the inability of bacteria to metabolize polyols into acids. Conclusion: The evidence suggests that sugar-free chewing gum has a caries-reducing effect. Further well-designed randomised trials are needed to confirm these findings.
\end{abstract}

Uniterms: Sugar free; Chewing gum; Caries; Xylitol; Sorbitol; Remineralisation.

\section{INTRODUCTION}

Several publications have suggested that sugar-free chewing gum has an anti-cariogenic effect ${ }^{1,5,8,16,35,41}$. Such effect is ascribed to the action of 2 factors: saliva stimulation through the chewing process and integration of dietary polyols ${ }^{8}$.

An increase in stimulated saliva flow has been associated with an increase in plaque $\mathrm{pH}^{19}$ and a higher salivary buffer capacity $^{8}$. Manning and $\operatorname{Edgar}^{25}$ (1993) reported that chewing sugar-free chewing gum directly after meals reduced the immediate plaque $\mathrm{pH}$ response and thus enhanced the potential of enamel remineralisation. Edgar and Geddes ${ }^{9}$ (1990) suggest further that the anti-cariogenic saliva effect may be further attributed to increased salivary bicarbonate, leading to higher buffer strength, as well as to an increased supply of alkaline substrates to the plaque. Furthermore, an increased salivary flow rate may significantly contribute to oral health through optimized cleansing of the tooth surface and to accelerated clearance of dietary sugars and plaque acids away from the tooth surface ${ }^{9,27}$.

The most common dietary polyols used in sugar-free chewing gum are Xylitol and Sorbitol ${ }^{8}$. Most oral bacteria do not metabolise Xylitol and Sorbitol to form $\mathrm{acid}^{8}$. Xylitol is a sugar alcohol derived from pentose sugar xylose and Sorbitol is a sugar alcohol derived from glucose ${ }^{8}$. Both elicit a gustatory reflex which, together with the chewing process, enhances saliva stimulation ${ }^{8}$. Unlike Sorbitol, Xylitol has been observed to exhibit a dose-related inhibition of S.mutans' growth in vitro ${ }^{2}$.

Based on these findings, a caries reduction in patients who chew sugar-free chewing gum is expected. The objective of this systematic literature review was to appraise existing evidence concerning a possible therapeutic / anti-cariogenic 
effect of sugar-free chewing gum for patients.

\section{MATERIALAND METHODS}

\section{Search strategy}

The literature search included 9 English databases: BIOMED CENTRAL, COCHRANE ORAL HEALTH REVIEWS, COCHRANE LIBRARY, DIRECTORY OF OPEN ACCESS JOURNALS, EXPANDED ACADEMIC ASAP PLUS, META REGISTER OF CONTROLLED TRIALS mRCT, PUBMED, SCIENCE-DIRECT, RESEARCH FINDINGS ELECTRONIC REGISTER - ReFeR and 2 Portuguese databases: BIBLIOGRAFIA BRASILEIRA EM ODONTOLOGIA - BBO, LITERATURA LATINOAMERICANA E CARIBENHA EM CIÊNCIAS DA SAÚDE - LILACS.

The English keywords "(chewing gum) AND (caries OR tooth decay) and (chewing gum) AND (caries risk)" and Portuguese keywords "(Goma mascar AND cári\$) and (Goma mascar) AND (risco cári\$)“ were used to search the English and Portuguese databases, respectively. The keywords were standardised in both languages for equivalent weight during the literature search. The time-search for publications in all databases was retrospectively unlimited until 09 June 2005. Publications were selected from the search results on the basis that their titles and abstracts were in accordance with the inclusion criteria: (i) relevance to the review objective; (ii) publication in English, German, Portuguese or Spanish. Where only a relevant title without a listed abstract was available, a full copy of the publication was assessed for inclusion. To be selected for review, publications had to fulfill all inclusion criteria.

\section{Publication review}

The review followed published guidelines ${ }^{39}$. All included

TABLE 1- Exclusion criteria for trials and literature reviews publications were assessed independently by two reviewers. Disagreements between the reviewers were solved through discussion, until final consent. Only in-vivo and in-situ trials were included. In-vitro studies were judged as providing insufficient evidence for therapy, since they carried the potential error of extrapolation of laboratory results to physiological effects in humans. For that reason they were not included. In cases of multiple reports from the same study, only the report covering the longest period was included. Published trials and literature reviews were assessed according to the exclusion criteria listed in Table 1. Publications were accepted as evidence only if they passed all exclusion criteria.

\section{Criteria for evidence value}

The evidence value of accepted articles was rated by application of a structured scoring system ${ }^{3,45}$ (Table 2). Following a similar validation system used by Zero, et al. ${ }^{45}$ (2001), included articles were rated as having 'strong', 'good' or 'reasonable' evidence value. The value of evidence depends on the amount of information provided by authors in their articles, to support the methodology used to obtain their results ${ }^{45}$. Accepted reviews were automatically rated as having strong evidence value. Since publications needed to pass all exclusion criteria in order to be accepted, accepted articles with lowest value ratings were still considered as offering reasonable evidence value.

\section{RESULTS}

After the literature search, 39 articles were found to be in accordance with the inclusion criteria and were selected for review. Of these, 14 were literature reviews and 25 were articles reporting on clinical trials.
Trials

Lack of randomisation

Drop-out rate $>33 \%$

\section{Literature reviews}

Focus on population or intervention not clearly stated in title and abstract

Patients and clinicians not 'blinded'

where possible and appropriate
Article methodology describes no clear inclusion and exclusion criteria for reviewed publications
No baseline data provided for both the control and the study group

Baseline differences not statistically adjusted

Clinically important outcomes for patients not assessed.
Article methodology describes no clear search strategy, key words and databases used and includes no study-by-study critique table or discussion of study qualities 


\section{Excluded articles}

After review, 14 literature reviews and 16 trials were excluded. Most of the excluded reviews ${ }^{1,4,7-9,11,14,29,35,36,38,41,44}$ were narrative in nature, lacking a stated literature search strategy and lacking stated inclusion and exclusion criteria for literature selection. Most reviews ${ }^{1,4,7,9,11,14,29,36,38,44}$ also lacked study-by-study critique tables. Five of the reviews ${ }^{7,11,14,36,38}$ had been published as editorials or short communications and one was a review of 1 single trial ${ }^{42}$. Five of the 14 reviews only discussed sugar-free chewing gum as part of an overall review theme; such as general chewing gum ${ }^{9,35}$, dental caries management ${ }^{1,4}$ and preventive dentistry ${ }^{44}$.

Of the 16 excluded trials, 11 were not randomised $^{13,15,18,19,21-24,33,37,43} ; 3$ trials $^{5,16,17}$ had a loss to follow up of more then $33 \%$ and 2 trials lacked operator blinding as part of their methodology ${ }^{10,30}$.

\section{Accepted articles}

A total of 9 articles reporting on trials were accepted. The data concerning the accepted articles are shown in Table 3. Two articles ${ }^{20,26}$ reported on results of 2 trials, each conducted with chewing gum of different polyol content, thus raising the number of accepted individual trials to 11 . From these, 8 trials followed in-vivo, and 3 in-situ study designs. The trials reported on the effects of using sugarfree chewing gum with Sorbitol ( 6 trials), Xylitol ( 2 trials) and Sorbitol/Xylitol combined (3 trials). The in-situ trials investigated the anti-cariogenic effect of enamel remineralisation on artificial carious lesions and in-vivo trials reported on caries reduction, mainly in permanent teeth (Table 3). The reported use of chewing gum in the accepted trials varied in frequency per day ( $3-7$ times) and duration (5-20 min). Five trials reported gum use immediately after meals $6,20,28,31,40$.

The results of the in-situ trials were conflicting. Two trials of good evidence value ${ }^{26}, 1$ with Sorbitol and 1 with Sorbitol/Xylitol chewing gum, reported statistically significant $(\mathrm{p}<0.05)$ enamel remineralisation after 21 days, while 1 trial with Sorbitol chewing gum of reasonable evidence value ${ }^{6}$ showed no significant remineralisation $(\mathrm{p}=$ 0.07 ) after 7 weeks. One in-vivo trial of good evidence value did not demonstrate any significant caries reduction with Sorbitol chewing gum ${ }^{12}$. All other in-vivo trials, 1 of strong evidence ${ }^{40}$ and 6 of good evidence value $20,28,31,32,34$, were able to demonstrate significant caries reduction after chewing of Sorbitol, Xylitol and Sorbitol/Xylitol chewing gum, as compared to no gum use. However, of these trials, 1 trial $^{32}$ reported such reduction for the occlusal tooth surfaces, only.

\section{DISCUSSION}

This systematic review was the first to include English as well as Portuguese databases in its literature search and to review articles in the 4 publication languages: English, German, Portuguese and Spanish, relating to the topic of

TABLE 2- Criteria for evidence values

\begin{tabular}{lll}
\hline Quality aspect & Criteria & Points \\
\hline Study setting: & $\begin{array}{l}\text { In - situ } \\
\text { In - vivo }\end{array}$ & 1 \\
& How the sample were collected & 1 \\
Article provides information on: & How examiners/patients were blinded & 1 \\
& How operators were trained or calibrated & 1 \\
& Examiners' reliability & 1
\end{tabular}

\begin{tabular}{lll} 
Sample drop-out rate: & $33-20 \%$ & 0 \\
& $10-19 \%$ & 2 \\
& $<10 \%$ & 3 \\
\hline Followed up period: & $<1$ year & 0 \\
& 1 year & 1 \\
& $>1$ year & 2 \\
\hline
\end{tabular}

Quality scores (Total number of points):

'Strong evidence' $=10-11$

'Good evidence' = 6-9

'Reasonable evidence' $=0-5$ 


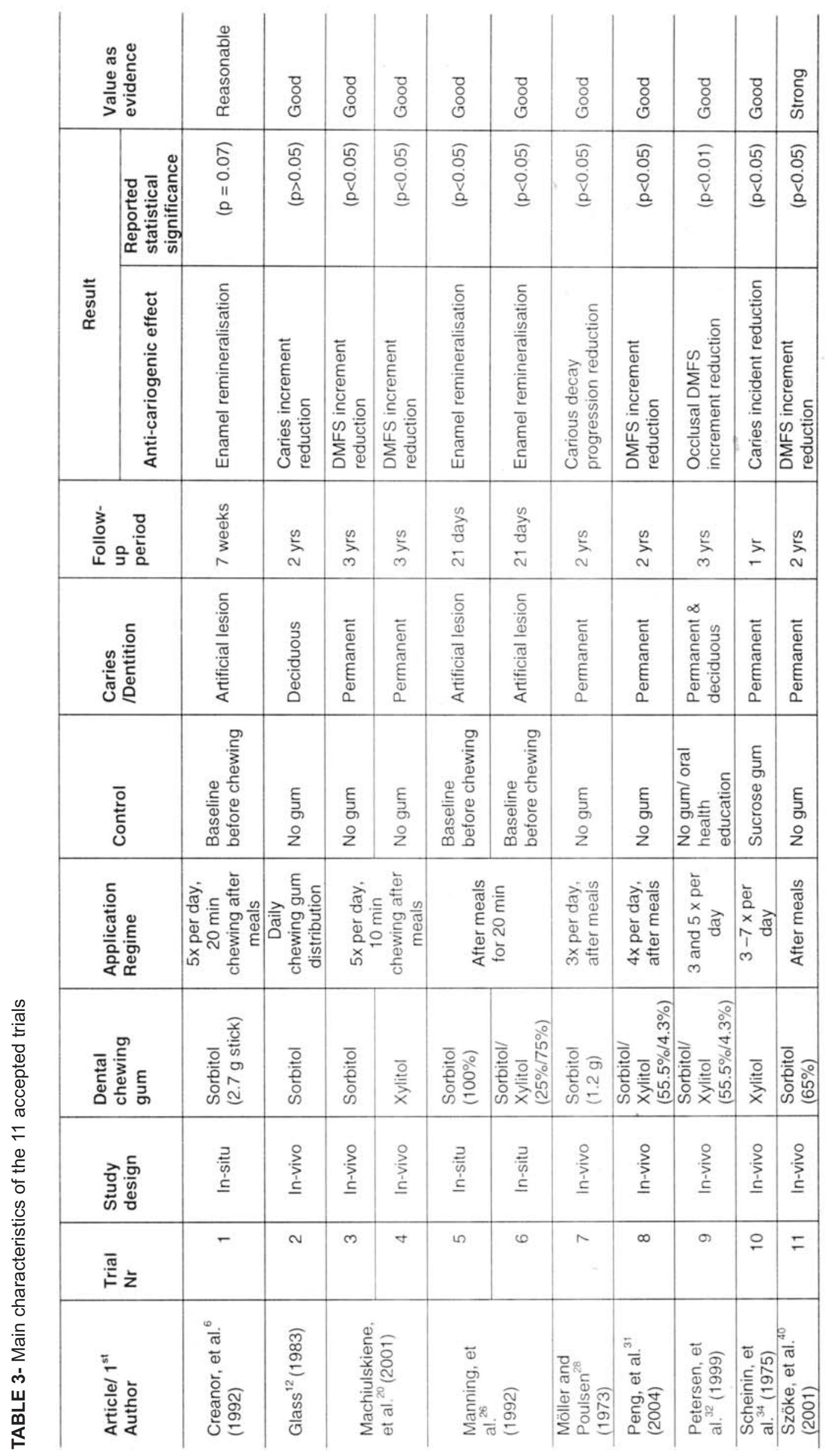


sugar-free chewing gum and caries. Moreover, the literature search was extended to cover multiple English databases. However, despite this broader approach, some limitations may have affected its results: (i) no hand-searching method was used; thus relevant studies may not have been identified; (ii) used search keywords might not have been broad enough in order to capture all articles listed in the databases. No meta-analysis was undertaken, owing to differences in the methodologies of the accepted trials.

One in-situ ${ }^{6}$ and 1 in-vivo trial ${ }^{12}$ out of the 11 separate trials accepted in this review did not report any anti-carious effect of sugar free chewing gum. The reason for not achieving any significant remineralisation $(p=0.07)$ in-situ after chewing Sorbitol gum 5 times per day for $20 \mathrm{~min}$, as compared to no gum use ${ }^{6}$, remains unclear. After 7 weeks, remineralisation in the test group was $18.2 \%$ and in the control group, $12.1 \%$. Remineralisation in the latter may have been aided by the use of an 1100-ppm-F (NaF) dentifrice given to both groups, thus reducing the effect of Sorbitol gum alone. The in-vivo study by Glass ${ }^{12}$ (1983) confirmed that Sorbitol chewing gum does not promote tooth decay. However, the results did not confirm any anti-cariogenic effect.

Two in-situ, and 7 in-vivo trials demonstrated significant enamel remineralisation and caries reduction, respectively. In contradiction to the in-situ trial of Creanor, et al. ${ }^{6}$ (1992), both in-situ trials by Manning, et al. ${ }^{26}$ (1992), with Sorbitol and Sorbitol/Xylitol chewing gum showed significant remineralisation of enamel. The contradicting outcome of these trials may be due to differences in technical aspects of the investigated artificial lesions. Such aspects may include lesion depth due to length of enamel placement in demineralising solution, as well as differences in enamel composition and structure, which vary between tooth sites. For this reason, the evidence found in our systematic literature review with regard to any significant remineralising effect of sugar-free chewing gum use on carious lesions is inconclusive.

Most of the accepted in-vivo trials showed significant caries reduction. Such reduction appeared to be independent of polyol-type, polyol-composition and concentration and chewing regimes. Machiulskiene, et al. ${ }^{20}$ (2001) observed no difference between polyol gum and a sugar-free control gum without polyol but a caries-reducing effect of the control gum when compared to no gum use. Petersen, et al. ${ }^{32}$ (1999) found a caries-reducing effect only for occlusal surfaces and Scheinin, et al. ${ }^{34}$ (1975) suggested that the anti-cariogenic effects of polyol were due to the lack of its suitability for micro biotic metabolism. Szöke, et al. $^{40}$ (2001) observed an anti-cariogenic effect after 20 min of chewing sugar-free chewing gum, especially immediately after meals: thus long after all soluble ingredients, such as polyols had been dissolved. It can therefore be concluded that the caries-reducing effect was not due to any therapeutic action of polyol but rather, to the chewing process itself and subsequent saliva stimulation.

According to our criteria, the evidence value of 9 accepted trials was good, while 1 trial was of strong, and 1 of reasonable evidence value. Of these 9 trials, 5 trials ${ }^{6,12,26,28,34}$ did not elaborate on examiner calibration and reliability in their methodologies. Such lack of information reduced the value of evidence found in this review. The quality and quantity of the found evidence suggests a further need for well-designed randomised trials to further confirm the caries-reducing effect of sugar-free chewing gum, as well as its underlying mechanisms. Further trials should provide data on any remineralising effect of polyol chewing gum and clarify whether specific polyols, such as Xylitol, have any anti-cariogenic, therapeutic effect.

\section{CONCLUSION}

The evidence suggests that chewing sugar-free chewing gum, used immediately after meals, reduces caries. The observed caries reduction can be ascribed to saliva stimulation throughout the chewing process, the lack of sucrose and the inability of bacteria to metabolise polyols into acids. No evidence for a direct therapeutic effect caused by Sorbitol or Xylitol was found. Further well-designed randomised trials are needed to confirm theses findings.

\section{ACKNOWLEDGMENT}

This review was supported by GC Asia and Midentistry.com

\section{REFERENCES}

1- Anderson MH, Bales DJ, Omnell KA. Modern management of dental caries: the cutting edge is not the dental bur. J Am Dent Assoc. $1993 ; 124: 37-44$

2- Assev S, Vegarud G, Rolla G. Growth inhibition of Streptococcus mutans strain OM7 176 by Xylitol. Acta Pathol Microbiol Immunol Scand [B]. 1980;88:61-3.

3- Bader JD, Shugars DA, Bonito AJ. A systematic review of the performance of methods for identifying carious lesion. J Public Health Dent. 2002;62:201-13.

4- Barber LR, Wilkins EM. Evidence-based prevention, management, and monitoring of dental caries. J Dent Hyg. 2002;76:270-5.

5- Beiswanger BB, Boneta AE, Mau MS, Katz BP, Proskin HM, Stookey GK. The effect of chewing sugar-free gum after meals on clinical caries incidence. J Am Dent Assoc. 1998;129:1623-6.

6- Creanor SL, Strang R, Gilmour WH, Foye RH, Brown J, Geddes DAM, et al. The effect of chewing gum use on in situ enamel lesion remineralization. J Dent Res. 1992;71:1895-900.

7- Done eating? Start chewing! Environ Nutr. 1993;16:1.

8- Edgar WM. Sugar substitutes, chewing gum and dental caries: a review. Br Dent J. 1998;184:29-32.

9- Edgar WM, Geddes DAM. Chewing gum and dental health: a review. Br Dent J. 1990;24:173-6. 
10 - Freitas RR, Oliveira JA, Taga EM, Buzalaf MAR. Efeito da goma de mascar contendo sacarose e do dentifrício fluoretado na remineralizacao in situ de lesões de cárie artificiais. Pesqui Odontol Bras. 2001;15:98-103.

11 - Gaby AR. Xylitol chewing gum for prevention of dental caries. Townsend letter for Doctors and patients. 2004;253-254:36.

12- Glass RL. A two-year clinical trial of Sorbitol chewing gum. Caries Res. 1983; 17:365-8.

13 - Honkala S, Honkala E, Tynjala J, Kannas L. Use of Xylitol chewing gum among Finnish schoolchildren. Acta Odontol Scand. $1999 ; 57: 306-9$

14- Hudnall M. Good nutrition, chewing gum can keep teeth healthy. Environ Nutr. 1994;17:2

15 - Hujoel PP, Mäkinen KK, Bennett CA, Isotupa KP, Isokangas PJ, Allen $\mathrm{P}$, et al. The optimum time to initiate habitual Xylitol gumchewing for obtaining long-term caries prevention. J Dent Res. 1999;78:797-803.

16- Isokangas P, Mäkinen KK, Tiekso J, Alanen P. Long-term effect of Xylitol chewing gum in the prevention of dental caries: a followup 5 years after termination of a prevention program. Caries Res. $1993 ; 27: 495-8$

17- Kandelman D, Gagnon G. A 24-month clinical study of the incidence and progression of dental caries in relation to consumption of chewing gum containing xylitol in school preventive programs. J Dent Res. 1990;69:1771-5

18 - Kashket S, Yaskell T, Lopez LR. Prevention of sucrose-induced demineralization of tooth enamel by chewing Sorbitol gum. J Dent Res. 1989;68:460-2.

19- Lee IK, Schachtele CF. Effect of gum chewing following food ingestion on the $\mathrm{pH}$ of interproximal dental plaque. Quintessence Int. $1992 ; 23: 455-9$

20 - Machiulskiene V, Nyvad B, Baelum V. Caries preventive effect of sugar-substituted chewing gum. Community Dent Oral Epidemiol. $2001 ; 29: 278-88$

21 - Mäkinen KK, Bennett CA, Hujoel PP, Isokangas PJ, Isotupa KP, Pape HR Jr, et al. Xylitol chewing gums and caries rates: a 40-month cohort study. J Dent Res. 1995;74:1904-13.

22- Mäkinen KK, Chiego DJ Jr, Allen P, Bennett C, Isotupa KP, Tiekso J, et al. Physical, chemical, and histologic changes in dentin caries lesions of primary teeth induced by regular use of polyol chewing gums. Acta Odontol Scand. 1998;56:148-56

23 - Mäkinen KK, Hujoel PP, Bennett CA, Isotupa KP, Mäkinen PL, Allen P. Polyol chewing gums and caries rates in primary dentition: a 24-month cohort study. Caries Res. 1996;30:408-17.

24- Mäkinen KK, Mäkinen PL, Pape HR Jr. Stabilisation of rampant caries: polyol gums and arrest of dentine caries in two long-term cohort studies in young subjects. Int Dent J. 1995;45:93-107.

25- Manning RH, Edgar WM. pH changes in plaque after eating snacks and meals, and their modification by chewing sugared- or sugar-free gum. Br Dent J. 1993;174:241-4.

26- Manning RH, Edgar WM, Agalamanyi EA. Effects of chewing gums sweetened with Sorbitol or a Sobitol/Xylitol mixture on the remineralisation of human enamel lesions in situ. Caries Res. 1992;26:104-9.
27- Mass E, Gadoth N, Harell D, Wolff A. Can salivary composition and high flow rate explain the low caries rate in children with familial dysautonomia? Pediatr Dent. 2002;24:581-6.

28 - Möller IJ, Poulsen S. The effect of sorbitol-containing chewing gum on the incidence of dental caries, plaque and gingivitis in Danish schoolchildren. Community Dent Oral Epidemiol. 1973;1:58-67.

29- Neder AC. O sorriso do chiclete. Rev ABO Nac. 1994;2:16-21.

30 - Oliveira AGRC, Costa ICC, Silva PR, Moimaz SAS. Ação da goma de mascar com xilitol sobre o $\mathrm{pH}$ da placa bacteriana após a ingestão de sobremesa à base de sacarose. RPG Rev Pos-grad. 1998;5:7-12.

31 - Peng B, Petersen PE, Bian Z, Tai B, Jiang H. Can school-based oral health education and a sugar-free chewing gum program improve oral health? Results from a two-year study in PR China. Acta Odontol Scand. 2004;62:328-32.

32 - Petersen PE, Razanamihaja N. Carbamide-containing polyol chewing gum and prevention of dental caries in schoolchildren in Madagascar. Int Dent J. 1999;49:226-30.

33 - Sas R, Dawes C. The intra-oral distribution of unstimulated and chewing-gum-stimulated parotid saliva. Arch Oral Biol. 1997;42:46974

34- Scheinin A, Mäkinen KK, Tammisalo E, Rekola M. Turku sugar studies XVIII: incidence of dental caries in relation to 1-year consumption of Xylitol chewing gum. Acta Odontol Scand. $1975 ; 33: 269-78$

35- Simons D. Chewing gum: trick or treat? A review of the literature. Dent Update. 1996;23:162-9.

36- Simonsen RJ. Bursting the chewing gum bubble. Quintessence Int. $1992 ; 23: 449$.

37- Slack GL, Duckworth R, Scheer B, Brandt RS, Ailianou MC. The effect of chewing gum on the incidence of dental diseases in Greek children: a 3-year study. Br Dent J. 1972;133:371-7.

38- Sugar-free gum and caries. Nutr Res News. 1998;17:11.

39- Sutherland SE. Evidence-based dentistry. Part V. Critical appraisal of the dental literature: papers about therapy. J Can Dent Assoc. $2001 ; 67: 442-5$

40 - Szöke J, Banoczy J, Proskin HM. Effect of after-meal sucrosefree gum-chewing on clinical caries. J Dent Res. 2001;80:1725-9.

41 - Tanzer JM. Xylitol chewing gum and dental caries. Int Dent J. 1995;45:65-76.

42- Tsao CE, Morgan MV. Does chewing sucrose-free chewing gum after meals reduce the development of carious lesions? Med J Aust. $2005 ; 182: 85-6$.

43- Vogel GL, Zhang Z, Carey CM, Ly A, Chow LC, Proskin HM. Composition of plaque and saliva following a sucrose challenge and use of an alpha-tricalcium-phosphate-containing chewing gum. J Dent Res. 1998;77:518-24.

44- Walsh LJ. Preventive dentistry for the general dental practitioner. Aust Dent J. 2000;45:76-82.

45-Zero D, Fontana M, Lennon AM. Clinical application and outcomes of using indicators of risk in caries management. J Dent Educ. 2001;65:1126-32. 